This item was submitted to Loughborough's Research Repository by the author.

Items in Figshare are protected by copyright, with all rights reserved, unless otherwise indicated.

\title{
A multi-function compact fuel reforming reactor for fuel cell applications
}

PLEASE CITE THE PUBLISHED VERSION

http://dx.doi.org/10.1016/j.fuel.2009.05.009

PUBLISHER

(C) Elsevier

VERSION

AM (Accepted Manuscript)

LICENCE

CC BY-NC-ND 4.0

REPOSITORY RECORD

Reed, James, Rui Chen, Christopher D. Dudfield, and Paul L. Adcock. 2011. "A Multi-function Compact Fuel Reforming Reactor for Fuel Cell Applications”. figshare. https://hdl.handle.net/2134/8304. 
This item was submitted to Loughborough's Institutional Repository by the author and is made available under the following Creative Commons Licence conditions.

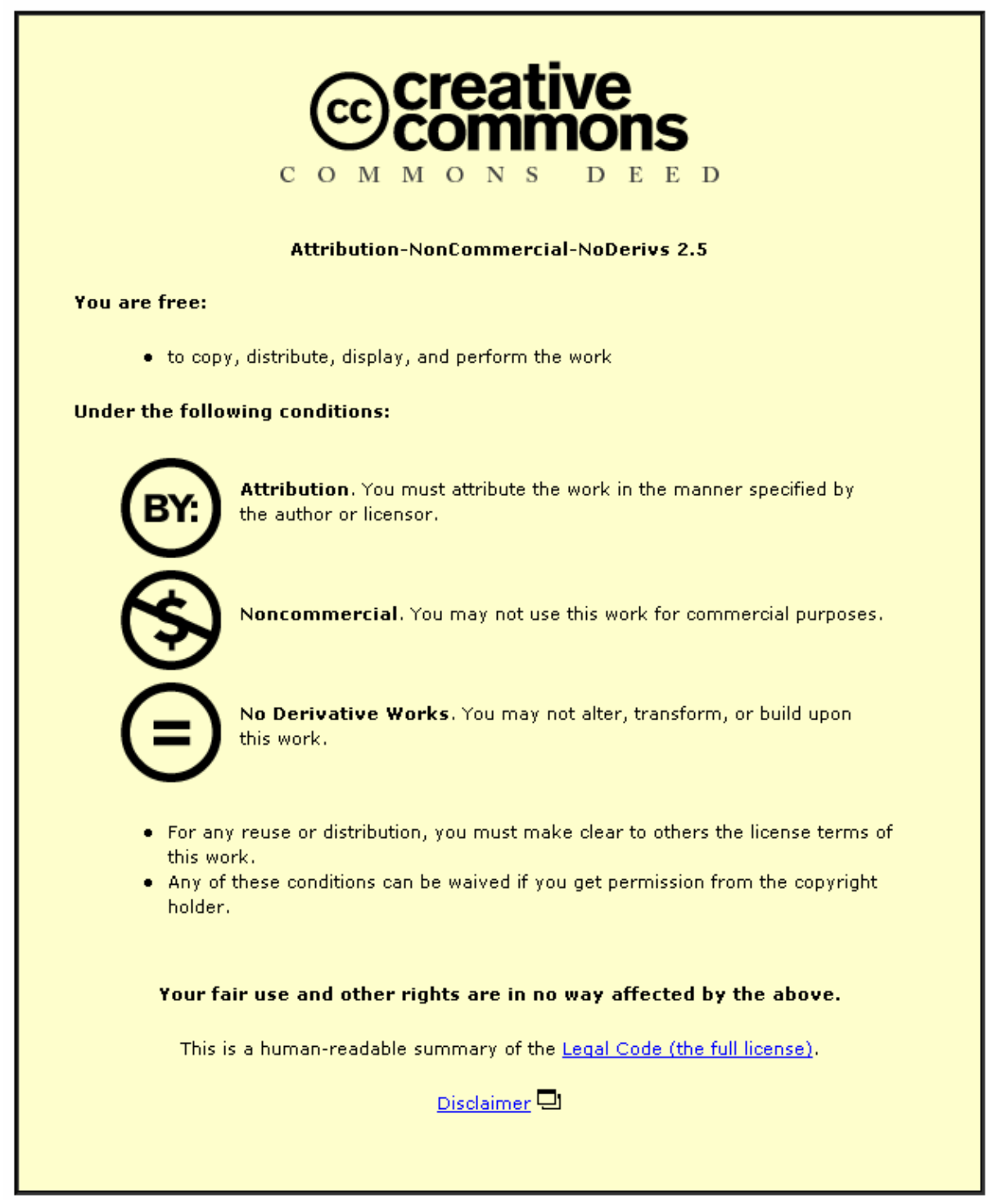

For the full text of this licence, please go to: http://creativecommons.org/licenses/by-nc-nd/2.5/ 


\title{
A Multi-function Compact Fuel Reforming Reactor for Fuel Cell Applications
}

James Reed, Rui Chen*

Department of Aeronautical and Automotive Engineering, Loughborough University, UK

Christopher Dudfield, Paul Adcock

Intelligent Energy Ltd., UK

* Corresponding author. TEL: (+44) 1509 227255, FAX: (+44) 1509 227275, E-mail address: r.chen@Lboro.ac.uk

\begin{abstract}
A multi-function compact chemical reactor designed for hydrocarbon steam reforming was evaluated. The reactor design is based on diffusion bonded laminate micro-channel heat exchanger technology. The reactor consists of a combustor layer, which is sandwiched between two steam reforming layers. Between the two function layers, a temperature monitor and control layer is placed, which is designed to locate the temperature sensors. The combustor layer has four individually controlled combustion zones each connected to a separate fuel supply. The reactor design offers the potential to accurately control the temperature distribution along the length of the reactor using closed loop temperature control. The experimental results show that the variance of temperature along the reactor is negligible. The conversion efficiency of the combustor layer is approximately $90 \%$. The heat transfer efficiency from combustion layer to reforming layers is $65 \%$ to $85 \%$ at $873 \mathrm{~K}$ and $673 \mathrm{~K}$, respectively. The heat transfer rate to the reforming layers is sufficient to support a steam reformation of propane at a rate of $0.7 \mathrm{dm}^{3} / \mathrm{min}$ (STP) with a steam to carbon ratio of 2 at $873 \mathrm{~K}$.
\end{abstract}

Keywords: Steam Reforming; LPG; Propane; Multi-Zone Combustor; Microchannel Heat Exchanger 


\section{Introduction}

The Solid Polymer Fuel Cell (SPFC) is seen as a potential clean power plant for a number of applications. The application that the fuel cell is used for is an example aside from the initial obvious cost issues. Although the automotive sector has invested significantly in the development of SPFC systems over the past decade, technology costs are still at present uncompetitive compared to that for the Internal Combustion Engine (ICE). Near term costs for SPFC systems have been reported to be approximately two orders of magnitude greater than the ICE on a $\$ / \mathrm{kW}$ basis.

Whilst a consideration of technology improvements and volume production will assist in reducing SPFC costs in the mid-long term, a more cost competitive market for SPFC technology is now seen as the stationary power market and distributed generation in particular. Stationary systems use the same SPFC stack technology that is used in automotive fuel cell systems. As such they need a hydrogen stream with a high level of purity (low sulphur and CO levels) to operate effectively. The source of the $\mathrm{H}_{2}$ fuel is still an area open to debate for automotive applications with some parties preferring the direct storage of $\mathrm{H}_{2}$ and others choosing the onboard fuel processor route.

However, for stationary power solutions the fuel processor is seen as the more obvious choice. The infrastructure to supply hydrocarbon fuels, be it natural gas or propane is already in place. The size and weight limitations placed on the fuel cell system are also less critical than if the system were to be used as an onboard $\mathrm{H}_{2}$ generation system. Figure 1 shows a typical SPFC system in combination with a hydrocarbon/alcohol fuel processor, in which the $\mathrm{H}_{2}$ fuel is liberated through chemical processing processes.

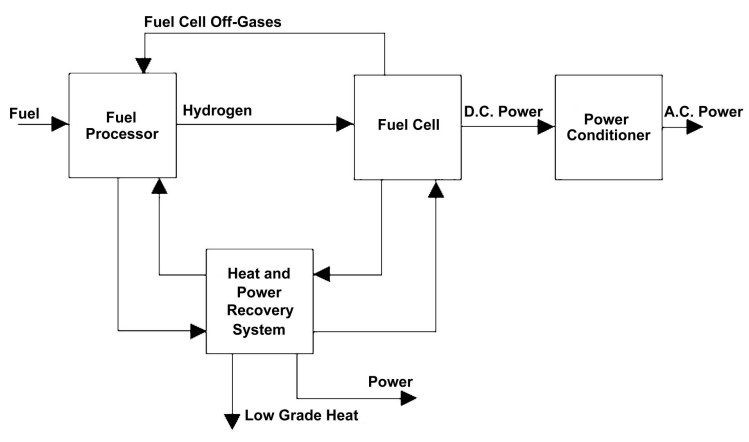

Figure 1: A typical SPFC system in combination with a hydrocarbon/alcohol fuel processor 
A 5-stage fuel processor reactor arrangement is shown in Figure 2. These stages include, desulphurisation, fuel reformer, a high and low temperature water gas shift reactor and CO removal (Additional stages of heat transfer between the stages are not shown). During the research reported in this paper, a multi-function compact fuel reforming reactor designed for fuel cell applications was investigated.

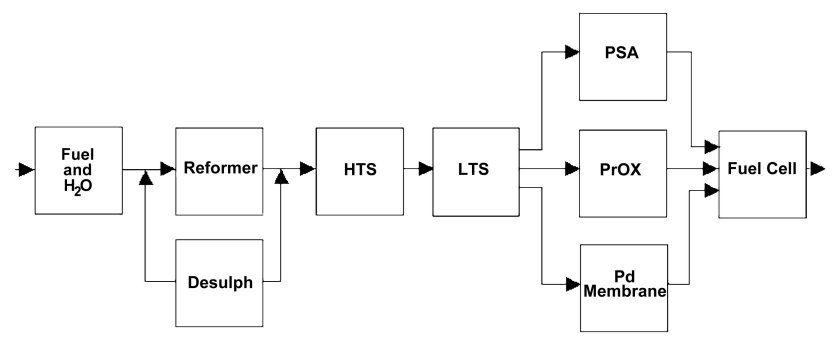

Figure 2: Overview for fuel processors

There are a number of potential chemical methods to reform hydrocarbon fuels and alcohols into a hydrogen rich gaseous fuel. These are: steam reforming, partial oxidation reforming, auto-thermal reforming, and other novel methods.

Steam reforming uses water to react with a hydrocarbon fuel to produce a hydrogen rich gaseous product. Carbon in the fuel is converted into $\mathrm{CO}$ by oxidation with the $\mathrm{O}_{2}$ contained in the steam. Hydrogen from both fuel and steam is released as a gas [Equation 1]. A catalyst is used to improve the reaction kinetics, which in turn lowers the reforming temperature and reduces the reactor size. The reaction temperature is critical since it determines the composition of the product gas i.e. the reformate. The reaction is endothermic so a continuous supply of heat to the reformer is required. This is performed by the integration of a combustor with the catalytic reformer.

$\mathrm{C}_{\mathrm{n}} \mathrm{H}_{\mathrm{m}}+\mathrm{nH}_{2} \mathrm{O} \rightarrow \mathrm{nCO}+(\mathrm{n}+\mathrm{m} / 2) \mathrm{H}_{2}$

Partial oxidation (POX) reforming systems rely on the reaction of the fuel with a limited amount of oxygen to prevent complete oxidation [Equation 2]. POX reforming allows for simpler design by removing the need for the external heat and water supplies required by steam reforming. Also, since no additional heat is required, potentially better transient performance is achievable. A wide range of hydrocarbon fuels can be reformed. The 
drawback is a relatively low $\mathrm{H}_{2}$ generation rate, since all the hydrogen gas has to be generated from the hydrocarbon fuel rather than partially from water steam. Additionally the $\mathrm{H}_{2}$ is further diluted by the remaining air in the reformate stream, which lowers fuel cell efficiency [1].

$\mathrm{C}_{\mathrm{n}} \mathrm{H}_{\mathrm{m}}+\frac{\mathrm{n}}{2}\left(\mathrm{O}_{2}+\frac{79}{21} \mathrm{~N}_{2}\right) \rightarrow \frac{\mathrm{m}}{2} \mathrm{H}_{2}+\mathrm{nCO}+\frac{\mathrm{n}}{2} \frac{79}{21} \mathrm{~N}_{2}$

Auto-thermal reforming (ATR) is fundamentally a combination of steam reforming and POX reforming. It utilises the heat generated from the POX reaction to keep the steam reforming reaction at the desired temperature. It is thermally neutral as a result. In practise a near auto-thermal operating point is reached [2].

Steam reforming produces the highest volume of $\mathrm{H}_{2}$ per unit hydrocarbon fuel of the methods described above. In addition, it can use the unused $\mathrm{H}_{2}$ from the fuel cell exhaust to partially fuel its combustor. This improves the overall system efficiency. Furthermore, since the reaction is endothermic, the reaction will not run away if any error with the control system occurs. Instead, it will naturally quench itself. This makes the steam reformer more efficient and safer than other methods.

\section{Reactor Design}

\subsection{Potential Technologies}

The reactor design used for fuel reforming has a significant effect on reforming efficiency, system start-up time and transient response. This is particularly important in steam reforming since the rate of reformation is limited by the rate of heat transfer to the reactants [3]. There are a number of potential technologies that can be used for the reactor design.

Packed bed reactors typically contain a series of tubes filled with a catalyst in the form of pellets or granules. The design is relatively simple and easy to maintain. They have been widely used in the industrial-scale steam or partial oxidation methods of reforming [4]. At portable-scale, the residence time of the reactant is limited and the performance of the reactor suffers as a result. The catalyst needs to be used much more effectively than at 
industrial-scale to maintain good reaction efficiency. A much more compact and efficient reactor design is needed [5].

Monolith reactors coated with catalyst offer several advantages over packed bed reformers. They have a higher surface area to volume, large frontal open area, low thermal mass, low heat capacity, low thermal expansion, high strength, and high temperature of operation. These advantages give the reactor quicker start-up, a higher conversion rate, reduced pressure drop along the reactor and improved thermal and mechanical shock resistance than the packed bed type of reactors. The drawbacks are lower content of active material per reactor volume and poor heat transfer performance due to the heat conductivity of ceramic material [1]. Monolith reactors have been favoured for ATR use (rather than steam reforming) where heat management is not as critical.

\subsection{New Compact Reactor}

Micro-channel heat exchangers are made of a diffusion bonded laminate. Inside the heat exchanger, the multilayer shims create the alternating micro-channels and fins (Figure 3). The micro-channel widths are determined by the thickness of the shim material whilst the heights and lengths of the channels are determined by the machined surface. The machining can be either by photochemical or stamping processes. This allows for a low cost method of making the shims. The shims are diffusion bonded together under high temperature and pressure $(1173 \mathrm{~K}, 27 \mathrm{MPa}$ for $4 \mathrm{~h}$ ) to yield a monolithic metal block that removes the need for gaskets and or other seals. This kind of heat exchanger has significantly higher heat transfer rates than most conventional designs. As the basis of a reactor for steam reforming, the heat energy required for the support of the reforming reaction, supplied from a combustor, can be efficiently transferred to the reaction side. The overall reforming system efficiency can then be improved.

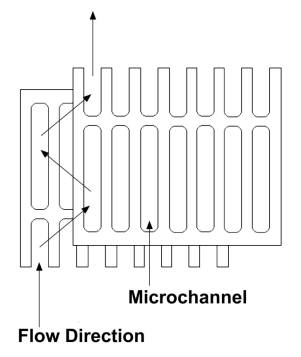

Figure 3: Micro-channel shims 
Based on this micro-channel heat exchanger technology, a new type of catalytic chemical reactor, shown in Figure 4, was developed.

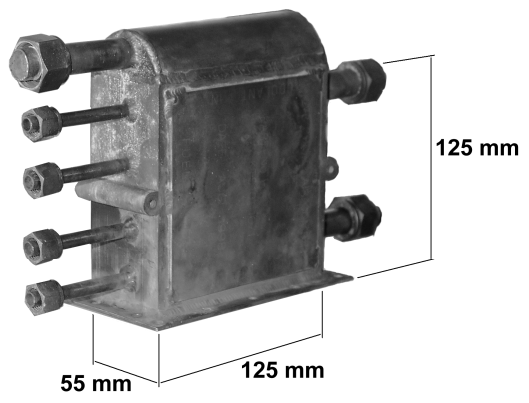

Figure 4: Micro-channel catalytic chemical reactor

Steam reforming is an endothermic reaction and as such needs to be supplied with thermal energy to be sustained. Most commercial reformers control the temperature at the exit of the reformer by measuring the temperature of the exit gases. This is an inefficient method of temperature control, since the temperature away from the exit is likely to be different than that required. In the newly developed micro-channel catalytic chemical reactor, the entire heat exchanger is divided into three groups of layers; a combustion layer, a temperature sensing layer, and a reforming layer as illustrated in Figure 5.

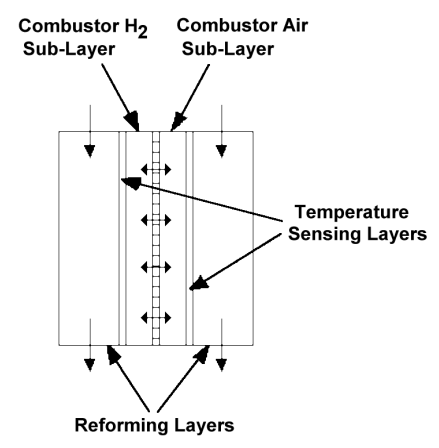

Figure 5: Internal structure of the micro-channel catalytic chemical reactor

The combustion layer, which is located in the centre, consists of fuel and air supply sub-layers in which the two sub-layers are inter-connected through a diffusion shim. The air is diffused into the fuel sub-layer and reacts with it to produce the heat required for the reforming reaction. The fuel sub-layer is split into four zones and washcoated with a platinum-based catalyst. The four zones each have an individual fuel feed and a common air feed 
as shown in Figure 6. By controlling the quantity of the fuel supplied to each individual zone, the heat released from each can then be continuously monitored and dynamically controlled. It avoids the formation of hot or cold spots and improves the reformer performance.

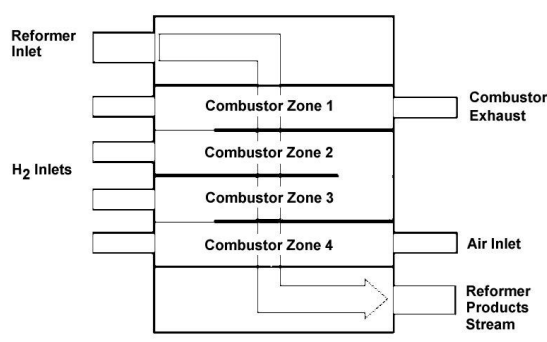

Figure 6: The combustion layer of the micro-channel catalytic chemical reactor

The temperature sensing layer is designed for the allocation of three groups of temperature sensors. These are located inside the reactor next to the combustion layer as shown in Figure 7.

In the combustion layer, zone 1 is adjacent to the inlet of the reforming reactants while zone 4 is directly open to the air supply to the combustion layer. In order to overcome the quenching effect of the inlet flows and maintain the desired reforming temperature in these zones, more fuel is needed here than for the middle zones and it was decided that the two middle zones would operate satisfactorily in unison.

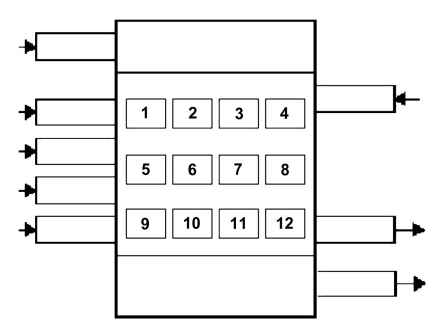

Figure 7: The temperature sensing layer of the micro-channel catalytic chemical reactor

In order to efficiently use the heat produced from the combustion layer, two reforming layers have been allocated, one on each side of the combustion layer. The configuration allows direct control of the reforming temperature with minimum lag time whilst making use of the maximum amount of heat available from the combustor. This results in fast transient responses and start up times, which are essential if the reformer is to be 
integrated into a complete system. The catalytic combustor will light off at room temperature (293 K) using simulated fuel cell exhaust gases.

\section{Experimental Study}

\subsection{Test Rig}

The reactor is of a stainless steel diffusion bonded laminate construction, which is ideally suited to the high temperatures necessary for the steam reforming of fuels such as LPG. Figure 8 shows the gas feed layout for the test rig. The fuel flow to the combustor is controlled by four solenoid valves acting as injectors. These split a common feed into four controllable streams.

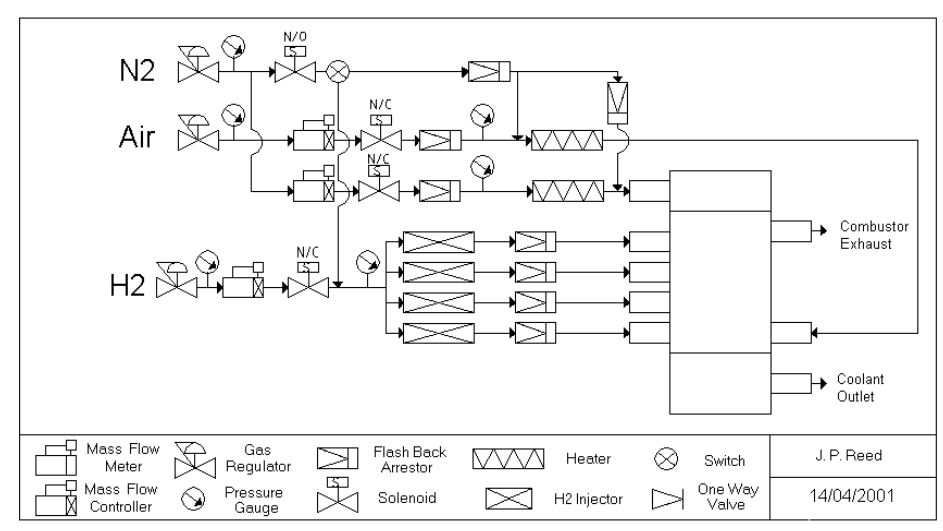

Figure 8: The gas feed layout for the test rig

LabVIEW ${ }^{\mathrm{TM}}$ was used to develop data acquisition combined control software for the multi-zone combustor. The control system uses a combination of closed loop proportional control and user defined control maps to provide individual control of each fuel injector allowing the longitudinal temperature gradient of the reactor to be controlled.

Early versions of the control maps used the desired temperature and the flow rate of coolant to determine the amount of $\mathrm{H}_{2}$ required to heat the reactor. These maps were initially developed using thermodynamic data and a simple power balance model. Later versions of these maps were modified using experimental data to make them more accurate. It was decided that just using two variables was not sufficient to satisfactorily control the reactor 
temperature. In order to improve the performance of the reactor under conditions of transient temperature, the first map was altered so that it produced a value for the flow rate of $\mathrm{H}_{2}$ depending on the temperature difference between the desired and measured temperature of the reactor. This then required the use of a second map to take into account the effects of coolant flow rate. The layout of the controller can be seen in Figure 9.

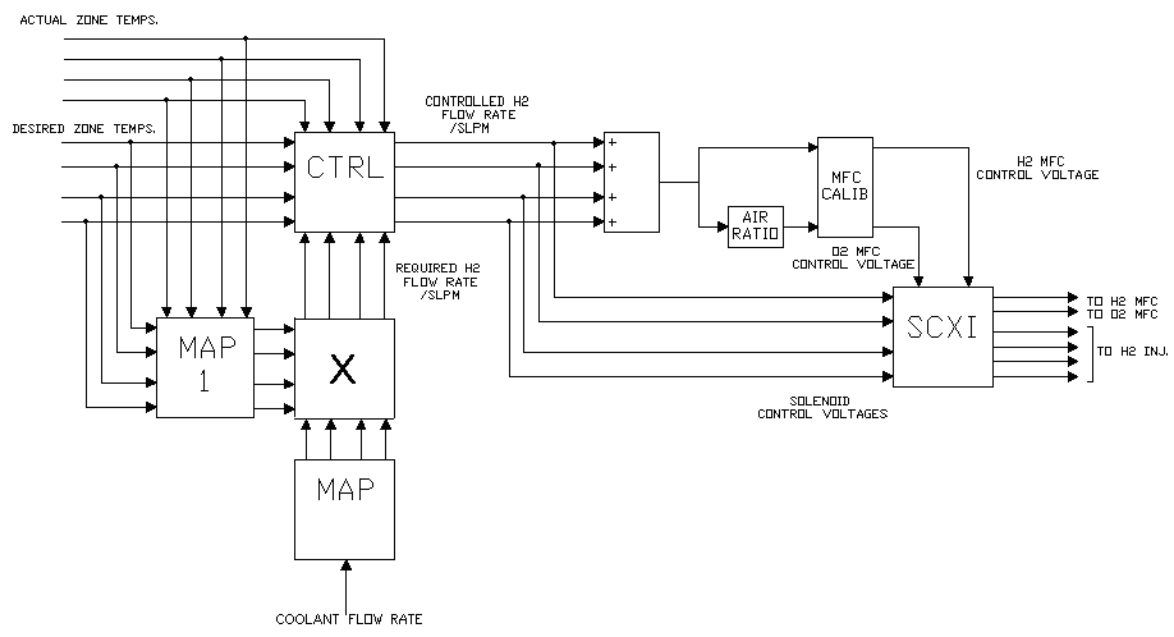

Figure 9: Controller schematic

The first control map takes the measured temperature of the reactor and cross references it with the desired temperature. This gives an initial estimate of the amount of $\mathrm{H}_{2}$ required to heat the reactor. The second control map modifies the initial estimate by allowing for the flow rate of coolant to the reactor. It does this by producing a modifying factor based on the coolant flow rate. This factor is then applied to the initial estimate from the first control map. This helps the controller deal with changes in coolant flow rate. The use of multiple control maps in this way is equivalent to using a 3D look-up table.

One percent of the estimated $\mathrm{H}_{2}$ flow rate from the control maps is used as an initial value for the proportional controller. The controller modifies the value according to the difference between the measured and desired reactor temperatures. This modified value is then added to the combined estimate from the control maps. Provided the control maps produce a value that is close to that required, the proportional controller acts as a dynamic trim on the map value. This means that the proportional controller acts as a fine tuner on the control map output. 
The overall fuel flow-rate is set using a mass flow controller (MFC) and the injectors are used to assign the correct amount of fuel to each combustor zone. The combustor mixture was controlled so as to mimic the proportion of fuel and $\mathrm{O}_{2}$ from typical fuel cell off gases. The outputs from the four controllers are summed and calibrated to produce a control signal for the $\mathrm{H}_{2}$ MFC. This signal is then modified by a user-defined ratio and converted into the corresponding MFC control signal for the air MFC. The user-defined ratio is used to set the fuel/air ratio for the combustor.

Operational limits are then applied to the control signals for the $\mathrm{H}_{2}$ injectors. This is necessary to stop the controller from asking for control signals that have no effect on the actuator. The solenoid control unit input is a 0-5 Vdc signal. However below $1.26 \mathrm{~V}$ the solenoid is effectively closed. Whilst, above 4.2V the solenoid is effectively wide open. For this reason the signals are passed through a saturation routine, which limits the upper and lower bounds of the control signal to $1.26 \mathrm{~V}$ and $4.2 \mathrm{~V}$ respectively.

The $\mathrm{H}_{2} \mathrm{O}$ produced by the combustor is condensed out by passing it through a heat exchanger and catch-pot. The combustor exhaust is then exhausted to atmosphere. The flow of $\mathrm{N}_{2}$ (used as a coolant to represent the reforming stream) was manually controlled via a mass flow controller. The reforming stream is also passed through a heat exchanger before being exhausted to atmosphere. The system is purged using $\mathrm{N}_{2}$ controlled by solenoids so that in the case of an emergency shut down, the entire system is purged.

\subsection{Temperature Control}

The micro-channel steam reforming reactor was first tested without temperature feedback control to ensure that light off could be achieved and the gas supply system was operational. During the test, equal amounts of $\mathrm{H}_{2}$ were fed to each combustor zone. On the reforming layer, nitrogen at a constant flow rate of $20 \mathrm{dm}^{3} / \mathrm{min}$ (STP) was passed through the reactor in a direction opposite to the combustor air supply. Figure 10 shows the average temperature measured by the three groups of temperature sensors as shown in Figure 7. 


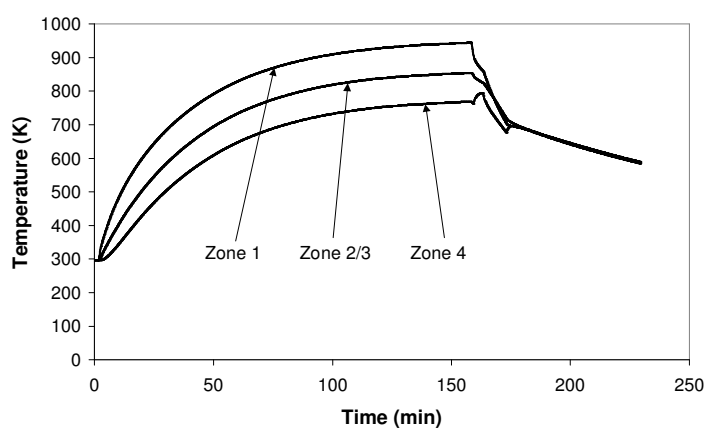

Figure 10: Average zone temperature measured by the three groups of temperature sensors

Zone 1 is adjacent to the nitrogen gas inlet but linked to the outlet of the combustion layer. From the test results, it can be seen that zone 1 has the highest temperature. Zone 4 is open to the air inlet. Although it is adjacent to the outlet of the reforming layer (where the nitrogen has been heated by the previous three zones), it has the lowest temperature. These test results showed that the gas movement and the heat release in the combustion layer have the dominant effect on the temperature distribution throughout the reactor.

Before the combustor was operated under closed loop control, it was necessary to determine whether the zones could be controlled individually and if the thermocouples were located correctly in the reactor. Therefore, the reactor was further tested by giving a $\mathrm{H}_{2}$ supply at a flow rate of $4 \mathrm{dm}^{3} / \mathrm{min}$ (STP) to each of the four inlets sequentially, in a procedure of 5 minutes operation to zone 1 , followed by 5 minutes stop, then shift to zone 2 and so on in turn. This allowed the reactor to cool between each addition of $\mathrm{H}_{2}$. The air was supplied to the reactor, synchronised to the $\mathrm{H}_{2}$ supply, at a $\mathrm{H}_{2}$ to air volume ratio of 1:5. Figures 11a-d show the measured rate of change of temperature as recorded by each individual thermocouple. 

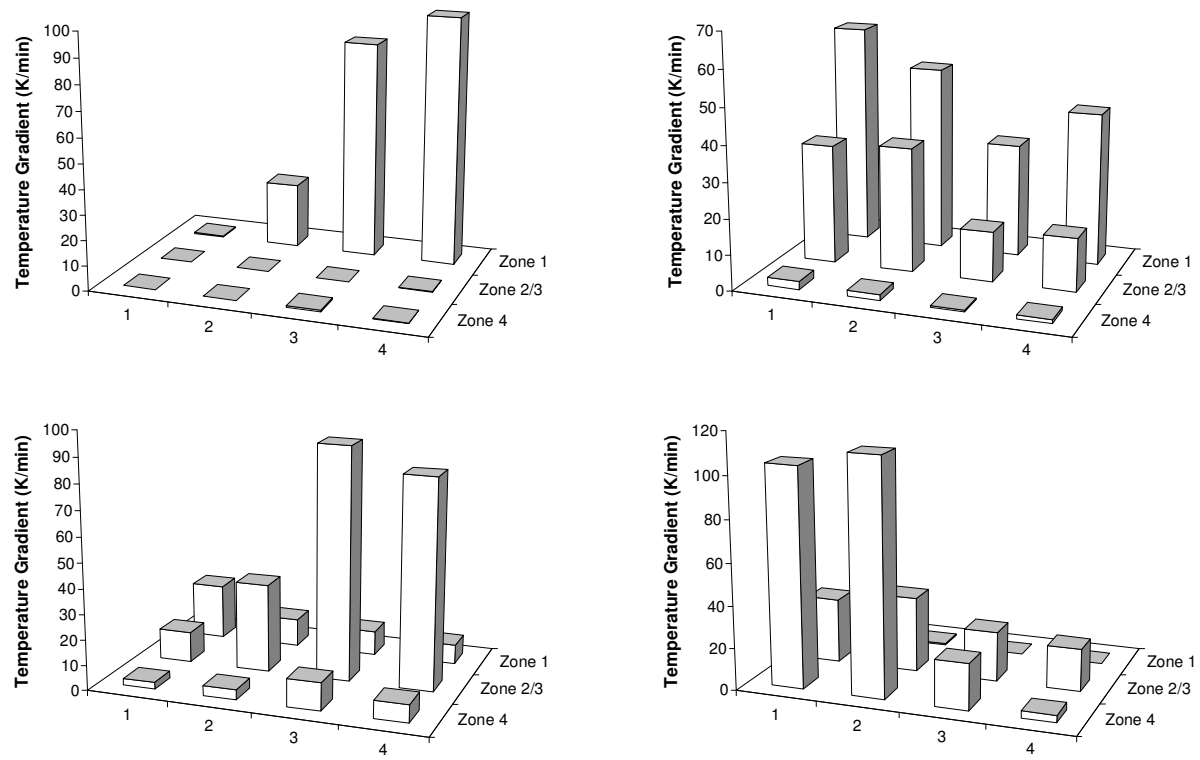

Figures 11a-d: The measured rate of change of temperature as recorded by each individual thermocouple

It can be seen in Figure 11a that when $\mathrm{H}_{2}$ is supplied to zone 1, the temperatures at the four positions inside zone 1 perform differently. Position 4 has the highest temperature gradient while the temperature at position 1 has hardly increased. From Figure 6, it can be seen that position 1 is geometrically next to the $\mathrm{H}_{2}$ inlet. Incidentally, the air flows in the same direction after passing the rest of the zones. The coincident flows, therefore, move the heat from position 1 to the downstream positions, and reduce its temperature. Position 4 is situated just before the outlet. It therefore accumulates the heat delivered through the flows and the heat generated due to the combustion reaction at that position. As a result it ends up with the largest temperature gradient among the four positions inside zone 1.

When $\mathrm{H}_{2}$ is supplied to zone 2 as shown in Figure 11b, the temperature gradient at positions 1 and 2 inside zone 1 are large and well above the gradients in zone 2. Again, this is because the airflow transfers some of the heat generated in zone 2 and some of the unburnt $\mathrm{H}_{2}$ downstream. However, inside zone 2, where the $\mathrm{H}_{2}$ is supplied, it appears that little combustion occurs at position 3. Clearly, this is due to the heading impact between the $\mathrm{H}_{2}$ supply and the airflow. The $\mathrm{H}_{2}$ is pushed away from the position by the airflow. The greatest temperature gradient in zone 2 is at position 2 , which potentially contains the highest $\mathrm{H}_{2}$ concentration. 
When $\mathrm{H}_{2}$ is supplied to zone 3, as seen in Figure 11c, the temperatures are monitored by the same group of temperature sensors as zone 2. Clearly, the temperature gradient at position 3 becomes the greatest followed by position 4. Again, this is mainly due to coincident flows of $\mathrm{H}_{2}$ and air.

Finally, when $\mathrm{H}_{2}$ is supplied to zone 4, as seen in Figure 11d, the gradients at positions 1 and 2 are the largest. Again, this is because of the heading impact between the $\mathrm{H}_{2}$ and airflows.

It can be seen that each zone, for the most part can be controlled individually. However, due to the internal flow interaction between the $\mathrm{H}_{2}$ and air, there is some spill over from each zone to the next downstream one. Figure 12 shows the test results obtained by dynamically adjusting the $\mathrm{H}_{2}$ supply to each individual zone. The temperatures shown in the figure were the averaged zone temperatures. These averaged temperatures were also used as the feedback to the control system for adjusting the $\mathrm{H}_{2}$ flows. The results showed that the zone average temperatures agree well at all three set points, $673 \mathrm{~K}, 823 \mathrm{~K}$ and $873 \mathrm{~K}$.

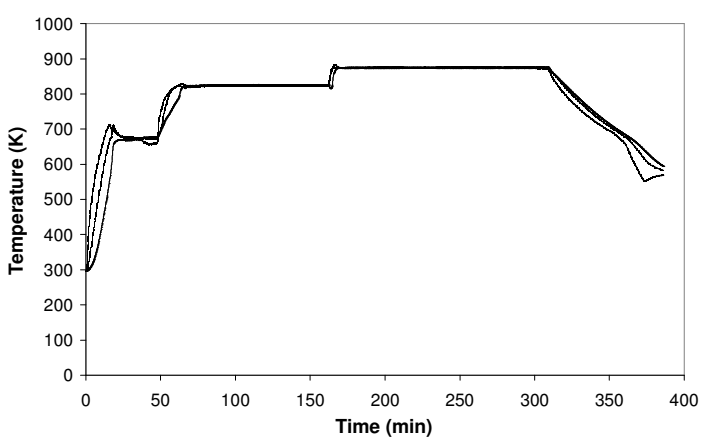

Figure 12: Averaged zone temperatures with dynamically $\mathrm{H}_{2}$ control

It can be seen that the system provides sufficient controllability to set the reactor temperature longitudinally along the reforming stream.

Figure 13 compares the longitudinal temperature distribution of the multi-zone reformer with that of a more traditional packed bed reformer design [5]. The improvement in temperature control can clearly be seen. The multi-zone approach allows the temperature to be accurately controlled and so by extension the reformate composition. 


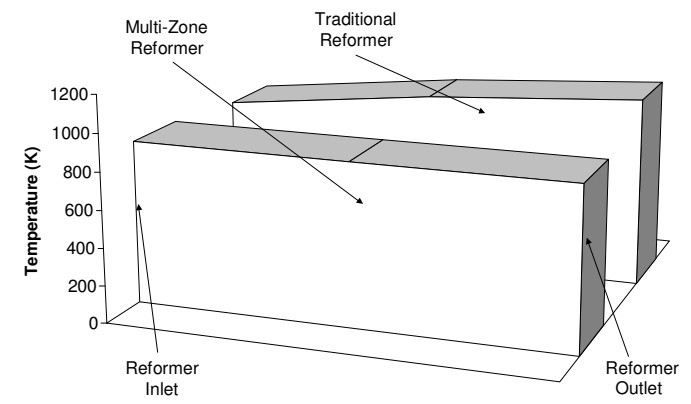

Figure 13: Comparison of longitudinal temperature distribution

\subsection{Heat Transfer Performance}

The motivation for the following tests was to determine the effectiveness of the micro-channel heat exchanger at distributing heat from the catalytic combustion of the $\mathrm{H}_{2}$ air mixture, to the reforming reactors on either side of the combustor. During the test, $\mathrm{H}_{2}$ and air in a ratio of $20 \% \mathrm{H}_{2}: 80 \%$ air, was fed to the combustor. The combustor temperature was controlled by varying the amount of $\mathrm{H}_{2}$ fed to each zone, with the airflow being adjusted accordingly. $\mathrm{N}_{2}$ was used as a coolant and was passed through the reforming reactors to take up the heat from the combustor. Measurements of the values required to perform a power balance on the reactor were taken once the temperatures of the various flows and the reactor had settled. The measured parameters were as follows.

1) Coolant inlet temperature $(\mathrm{K})$

2) Coolant exit temperature $(\mathrm{K})$

3) Air inlet temperature $(\mathrm{K})$

4) Combustor exhaust temperature (K)

5) Coolant flow rate $\left(\mathrm{dm}^{3} / \mathrm{min}(\mathrm{STP})\right)$

6) Air flow rate $\left(\mathrm{dm}^{3} / \mathrm{min}(\mathrm{STP})\right)$

7) $\mathrm{H}_{2}$ flow rate $\left(\mathrm{dm}^{3} / \mathrm{min}(\mathrm{STP})\right)$

8) Combustor temperature $(\mathrm{K})$

9) Ambient temperature (K)

10) $\mathrm{H}_{2} \mathrm{O}$ (liquid) produced from $\mathrm{H}_{2}$ combustion $\left(\mathrm{cm}^{3}\right)$ 
With the exception of the $\mathrm{H}_{2} \mathrm{O}$ produced from the combustion of the $\mathrm{H}_{2}$ the above parameters were averaged over a time of 10 min. The amount of $\mathrm{H}_{2} \mathrm{O}$ recorded was the total $\mathrm{H}_{2} \mathrm{O}$ produced over the 10 min period. By comparing the amount of $\mathrm{H}_{2} \mathrm{O}$ produced with that which would have been produced by complete combustion of the $\mathrm{H}_{2}$, the percentage of $\mathrm{H}_{2}$ combusted was calculated and hence the $\mathrm{H}_{2}$ conversion efficiency. Figures 14 and 15 show the effects of combustor temperature and coolant flow rate on the $\mathrm{H}_{2}$ conversion efficiency respectively.

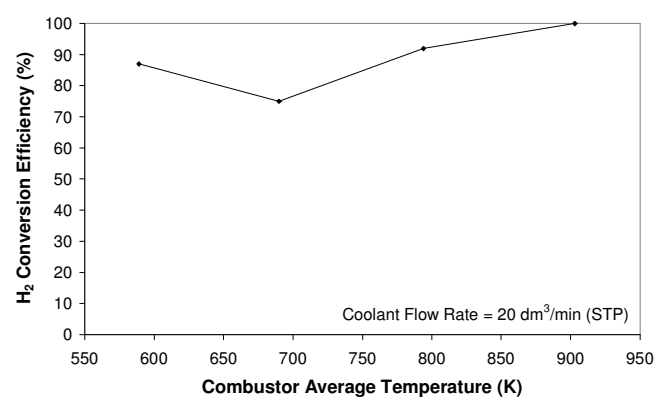

Figure 14: $\mathrm{H}_{2}$ conversion efficiency at varying combustor temperature

It can be seen there is a trend which suggests that the greater the combustor temperature, the higher the $\mathrm{H}_{2}$ conversion efficiency becomes. It can be seen that $\mathrm{H}_{2}$ conversion at $573 \mathrm{~K}$ does not follow the observed trend. This is due to experimental error regarding the calculation of $\mathrm{H}_{2}$ conversion based on the collected $\mathrm{H}_{2} \mathrm{O}$ from the combustor exhaust, which can never be exact. On the other hand, the influence of the coolant flow rate on the $\mathrm{H}_{2}$ conversion is relatively small. There does appear to be a trend of increasing $\mathrm{H}_{2}$ conversion with $\mathrm{N}_{2}$ flow rate but this is by no means clear and can be accounted for in the same way that as the anomaly in Figure 14. It can be seen that the averaged $\mathrm{H}_{2}$ conversion efficiency is in the region of $90 \%$.

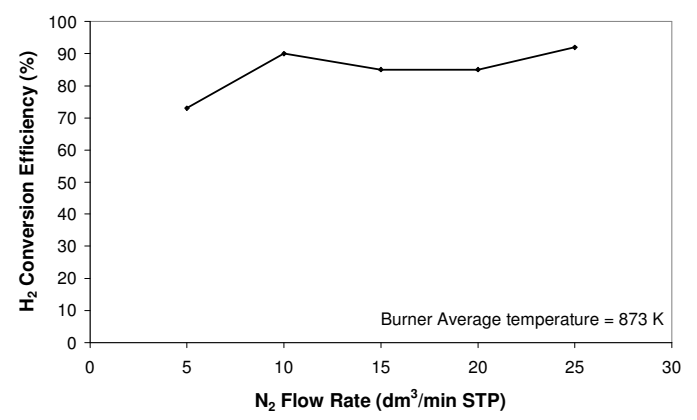

Figure $15: \mathrm{H}_{2}$ conversion efficiency at varying coolant flow rate 
To calculate the heat transfer efficiency a thermal power balance of the reactor was performed. The thermal power transferred to the reforming reactor, which is the thermal power obtained by the reforming streams was calculated by

$$
P_{\text {reactor }}=\dot{m}_{R} \times \int_{T_{1}}^{T_{2}} C_{p, R} d T
$$

where $\dot{m}_{R}$ is the flow rate of the reforming stream, $C_{p, R}$ is the specific heat capacity at constant pressure, $T_{1}$ is the reformer inlet temperature, and $T_{2}$ is the observed outlet temperature of the reforming stream. The pressure drop across the reactor at the operating flow rates was negligible.

The thermal power produced from the combustion of the $\mathrm{H}_{2}$ in the combustion layer of the reactor was obtained as

$$
P_{\text {burner }}=\left(\dot{m}_{\mathrm{H}_{2}} \eta_{b} \Delta H_{f_{\mathrm{H}_{2} \mathrm{O}}}\right)+P_{\text {air }}-P_{\text {exhaust }}
$$

where $\dot{m}_{\mathrm{H}_{2}}$ is the flow rate of $\mathrm{H}_{2}$ in moles per second, $\eta_{b}$ is the $\mathrm{H}_{2}$ conversion efficiency of the combustor, and $\Delta H_{f_{\mathrm{H}_{2} \mathrm{O}}}$ is the enthalpy of formation of $\mathrm{H}_{2} \mathrm{O}$ at the combustor temperature. $P_{\text {air }}$ and $P_{\text {exhaust }}$ are the thermal power in the combustor air supply and combustor exhaust respectively. They were calculated using the same method as $P_{\text {reactor }}$ with the appropriate temperatures and specific heats for each stream used.

The heat transfer efficiency was then defined as

$$
\eta_{\text {HEX }}=\frac{P_{\text {reactor }}}{P_{\text {burner }}}
$$

The heat flux from combustor to reforming streams was calculated as 
$q=\frac{P_{\text {reactor }}}{A}$

where $A$ is the area available for heat transfer.

Figure 16 shows the effect of the temperature of the combustion layer of the reactor on the heat transfer efficiency and heat flux. The reforming stream flow rate was set to $20 \mathrm{dm}^{3} / \mathrm{min}$ (STP). It can be seen that the heat transfer efficiency decreases as the average temperature of the combustor increases. At a combustor temperature of $673 \mathrm{~K}$, the heat transfer efficiency peaks at $85 \%$. As temperature increases, it decreases to a level of $65 \%$ at $873 \mathrm{~K}$. The decrease in heat transfer efficiency is due to the increase in the $\mathrm{H}_{2}$ conversion efficiency at high temperatures. Figure 17 shows temperature difference between the reforming stream and the average combustor temperatures, against the average combustor temperature. It can be seen that the temperature difference increases as combustor temperature increases, which means that the temperature increase of the reforming stream is not as high as that of the combustor. This indicates that the increase in temperature of the reforming stream is not sufficient to overcome the effect of the increased $\mathrm{H}_{2}$ conversion rate. Therefore, the heat transfer efficiency of the reactor decreases.

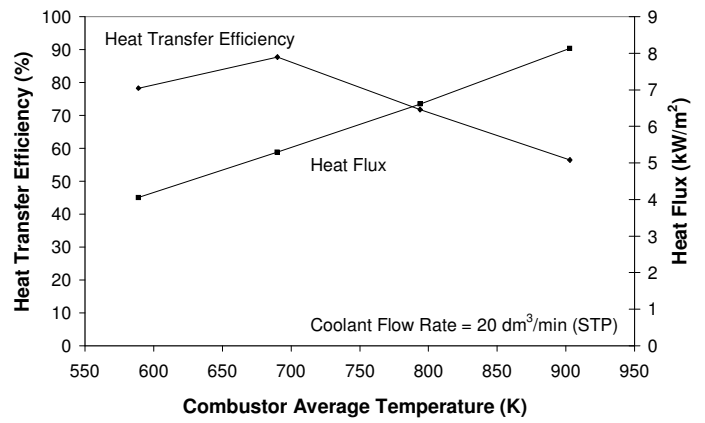

Figure 16: Effect of combustor temperature

The heat flux increase is mainly due to the fact that the $\mathrm{H}_{2}$ conversion efficiency is generally proportional to the temperature of the combustor as shown in Figure 14. As temperature increases, more heat is generated from the combustor. As a result, both heat flux and the thermal power of the combustor increase. 


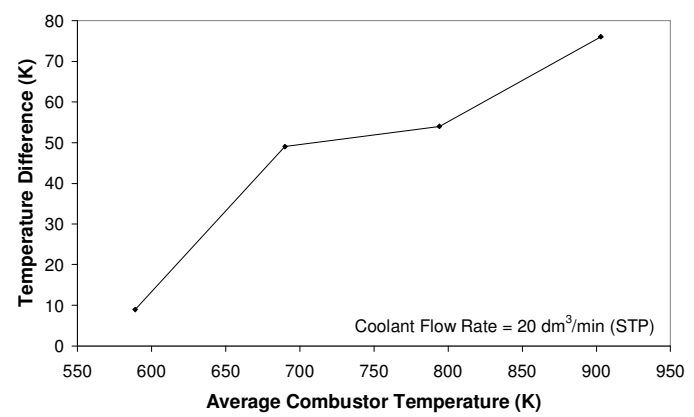

Figure 17: Temperature difference between the reforming stream and the average combustor temperatures.

Figure 18 shows the effect of the reforming stream flow rate on the heat transfer efficiency and the heat flux. The reforming stream was tested using $\mathrm{N}_{2}$. The combustor temperature remained constant at $873 \mathrm{~K}$ throughout the test by controlling the amount of $\mathrm{H}_{2}$ supplied to the combustor. It can be seen that as the flow rate of the reforming stream increases so does the heat transfer efficiency and the heat flux. This is due to the fact that the increased reforming flow is able to absorb more heat from the combustor, and the controller responds by increasing the amount of $\mathrm{H}_{2}$ to the combustor. Since the $\mathrm{H}_{2}$ conversion efficiency of the combustor is approximately independent of reforming stream flow rate, the thermal power of the combustor increases, and the heat flux rises.

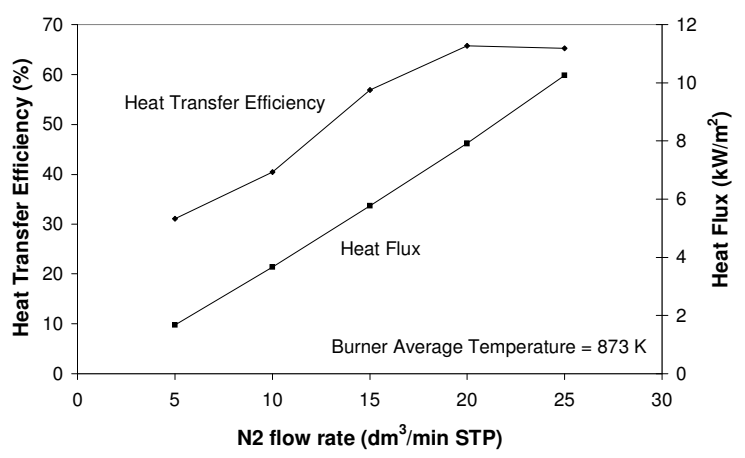

Figure 18: Effect of the reforming stream flow rate

Figure 19 shows temperature difference between the reforming stream and the average combustor temperatures, against the $\mathrm{N}_{2}$ flow rate. As the $\mathrm{N}_{2}$ flow rate increases, the temperature difference decreases. This is because the higher flow rates of $\mathrm{N}_{2}$ enable more energy to be absorbed from the combustor and therefore improves the heat transfer efficiency. 


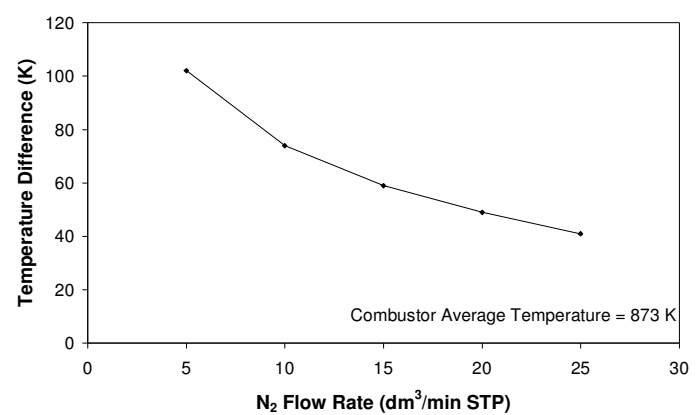

Figure 19: Temperature difference between the reformer stream and the average combustor temperature.

The thermal power transferred to the reforming stream at a combustor average temperature of $873 \mathrm{~K}$ and a $\mathrm{N}_{2}$ flow rate of $25 \mathrm{dm}^{3} / \mathrm{min}$ (STP) was approximately $320 \mathrm{~W}$. This is enough thermal power to support the steam reforming of $0.7 \mathrm{dm}^{3} / \mathrm{min}$ (STP) propane at a molar steam to carbon ratio of 2 and a temperature of $873 \mathrm{~K}$. Therefore, the reactor is capable of a sufficiently high rate of heat transfer for use as a steam reformer. In addition, as the flow rate of the reforming stream increases the heat flux also increases. This suggests that the reactor is capable of supporting higher flow rates of propane.

\section{Conclusions}

A micro-channel steam reformer was designed and built. Control and data acquisition software was produced to enable the operation of the steam reformer. Using this software the temperature of each combustor zone can be individually controlled.

It was found that zones 1 and 4 , which are positioned at inlet and exit of the reforming stream, respectively, required the most control input. Zones 2 and 3, which are located in the middle of the combustor, could be controlled together without a detrimental effect on the controllers' performance. Additionally, it was found that the flow of the gases in the combustion layer adversely affects the temperature distribution in the combustor. However, it was shown that the multi-zone combustor layout provides accurate temperature control along the length of the reformer. This improves the traditional reformer designs. The catalytic combustor works effectively with approximately $90 \%$ of the $\mathrm{H}_{2}$ converted. The heat transfer efficiency of the reactor between the combustor and reforming layer was found to be in the region of $65 \%$ to $85 \%$ at a temperature of $873 \mathrm{~K}$ to $673 \mathrm{~K}$, respectively. 
The reactor is capable of a sufficient rate of heat transfer for use as a steam reformer. In addition, as the flow rate of reforming stream increases the heat flux also increases. This suggests that the reactor is capable of supporting higher flow rates of reforming fuel than demonstrated here.

\section{References}

${ }^{1}$ B. Lindstrom, L. J. Pettersson - Steam Reforming of Methanol over Copper-Based Monoliths: The Effects of Zirconia Doping, J. Power Sources 106 (2002) 265-273

${ }^{2}$ N. Edwards, S.R. Ellis, J.C. Frost, S.E. Golunski, A.N.J. van Keulen, N.G. Lindewald, J.G. Reinkingh - Onboard hydrogen generation for transport applications: the HotSpot ${ }^{\mathrm{TM}}$ methanol processor, J. Power Sources 71 (1998) 123-128

${ }^{3}$ S. Ahmed, M. Krumpelt - Hydrogen from Hydrocarbon Fuels for Fuel Cells - Int. J. Hydrogen Energy 26 (2001) 291-301

${ }^{4}$ A. Dicks, J. Larminie - Reforming of Fossil Fuels (Status Survey), Proc. Fuel Cell 2000 0-14/07/2000, Lucerne Switzerland

5 A. Heinzel, B. Vogel, P. Hubner - Reforming of Natural Gas - Hydrogen Generation for Small Scale Stationary Systems, J. Power Sources 105 (2002) 202-207 